\title{
Prevalence of Anemia and Its Associated Factors among Pregnant Women Attending Antenatal Care in Health Institutions of Arba Minch Town, Gamo Gofa Zone, Ethiopia: A Cross-Sectional Study
}

\author{
Alemayehu Bekele, ${ }^{1}$ Marelign Tilahun, ${ }^{2}$ and Aleme Mekuria ${ }^{1}$ \\ ${ }^{1}$ Department of Public Health Nursing, Arba Minch College of Health Sciences, P.O. Box 155, Arba Minch, Ethiopia \\ ${ }^{2}$ Department of Public Health, College of Health Sciences, Debre Tabor University, P.O. Box 272, Debre Tabor, Ethiopia \\ Correspondence should be addressed to Aleme Mekuria; alemmekurishet@gmail.com
}

Received 8 November 2015; Revised 15 January 2016; Accepted 18 January 2016

Academic Editor: Eitan Fibach

Copyright (C) 2016 Alemayehu Bekele et al. This is an open access article distributed under the Creative Commons Attribution License, which permits unrestricted use, distribution, and reproduction in any medium, provided the original work is properly cited.

\begin{abstract}
Background. Anemia during pregnancy is a major cause of morbidity and mortality of pregnant women in developing countries and has both maternal and fetal consequences. Despite its known serious effect on health, there is very little research based evidence on this vital public health problem in Gamo Gofa zone in general and in Arba Minch town of Southern Ethiopia in particular. Therefore, this study aims to assess the prevalence and factors associated with anemia among pregnant women attending antenatal care in health institutions of Arba Minch town, Gamo Gofa zone, Southern Ethiopia. Method. Institution-based, cross-sectional study was conducted from February 16 to April 8, 2015, among 332 pregnant women who attended antenatal care at government health institutions of Arba Minch town. Interviewer-administered questionnaire supplemented by laboratory tests was used to obtain the data. Bivariate and multivariate logistic regressions were used to identify predictors of anemia. Result. The prevalence of anemia among antenatal care attendant pregnant women of Arba Minch town was 32.8\%. Low average monthly income of the family $(\mathrm{AOR}=4.0 ; 95 \% \mathrm{CI}: 5.62-11.01)$, having birth interval less than two years (AOR $=3.1 ; 95 \% \mathrm{CI}$ : 6.01, 10.23), iron supplementation $(\mathrm{AOR}=2.31 ; 95 \% \mathrm{CI}: 7.21,9.31)$, and family size $>2(\mathrm{AOR}=2.8 ; 95 \% \mathrm{CI}: 1.17,6.81)$ were found to be independent predictors of anemia in pregnancy. Conclusion. Anemia is found to be a moderate public health problem in the study area. Low average monthly income, birth interval less than two years, iron supplementation, and large family size were found to be risk factors for anemia in pregnancy. Awareness creation towards birth spacing, nutritional counselling on consumption of iron-rich foods, and iron supplementation are recommended to prevent anemia among pregnant women with special emphasis on those having low income and large family size.
\end{abstract}

\section{Background}

Anemia is defined as a decrease in the concentration of circulating red blood cells or in the haemoglobin concentration and a concomitant impaired capacity to transport oxygen. It has multiple precipitating factors that can occur in isolation but more frequently cooccur. These factors may be genetic, such as haemoglobinopathies; infectious diseases, such as malaria, intestinal helminths, and chronic infection or nutritional deficiency, which includes iron deficiency as well as deficiencies of other vitamins and minerals, such as folate, vitamins $\mathrm{A}$ and $\mathrm{B} 12$, and copper [1].
Anemia is a global public health problem affecting both developing and developed countries with major consequences on human health as well as social and economic development. It occurs at all stages of the life cycle but is more prevalent in pregnant women and young children [2]. Although the prevalence of anemia is estimated at $9 \%$ in countries with high development, in countries with low development the prevalence is $43 \%$. Children and women of reproductive age are most at risk, with global anemia prevalence estimates of $47 \%$ in children younger than 5 years, $42 \%$ in pregnant women, and $30 \%$ in nonpregnant women aged 15-49 years and with Africa and Asia accounting for 
more than $85 \%$ of the absolute anemia burden in high risk groups [3].

Anemia during pregnancy is a major cause of morbidity and mortality of pregnant women in developing countries and has both maternal and fetal consequences. Anemia during pregnancy is considered severe when haemoglobin concentration is less than $7.0 \mathrm{~g} / \mathrm{dL}$, moderate when haemoglobin falls between 7.0 and $9.9 \mathrm{~g} / \mathrm{dL}$, and mild when haemoglobin concentration is from 10.0 to $11 \mathrm{~g} / \mathrm{dL}[1,3-5]$.

Low maternal haemoglobin levels are associated with increased risk of preterm delivery, Low Birth Weight (LBW) babies, APGAR score $<5$ at $1 \mathrm{~min}$, and intrauterine growth retardation (IUGR). Haemoglobin adjusted for altitude and smoking status in Ethiopia shows that $22 \%$ of pregnant women in Ethiopia are anemic and the prevalence varies by residence and educational and wealth status of women. The Health Sector Development Plan IV (HSDP IV) in Ethiopia targets reducing the national level of anemia to $12 \%$ $[3,6]$.

Nutritional, genetic, and infectious diseases are contributing factors for anemia. However, iron deficiency is the cause of $75 \%$ of anemia cases. The understanding of how these factors vary by geography, level of development, and other social and economic factors will make it easier to design interventions that are more effective and integrative in addressing multiple contributing factors at the same time $[1,7]$.

In Ethiopia, even though the HSDP IV target is to reduce anemia prevalence nationally to 12 percent, still anemia is severe problem and affecting $22 \%$ of pregnant mothers $[6,8]$. Given the multifactorial nature of this disease, correcting anemia often requires an integrated approach. In order to effectively combat anemia, the contributing factors must be identified and addressed. The availability of local prevalence statistics has a major role in the management and control of anemia in pregnancy. Besides the limited studies done in Ethiopia, the prevalence of anemia in pregnant women in our study area is not well known so far. Therefore, this study aims at assessing the prevalence of anemia and its associated factors among pregnant women attending ANC in health institutions of Arba Minch town, Gamo Gofa zone, Southern Ethiopia.

\section{Methods}

2.1. Study Area. The study was conducted at Arba Minch General Hospital, Arba Minch, and Secha Health Centers in Arba Minch town, Ethiopia. All the three health institutions are located in Arba Minch town which is the capital of Gamo Gofa zone. The catchment area of the two health centres is Arba Minch town and that of the hospital is Gamo Gofa zone. The altitude of the area is $1285 \mathrm{~m}$ (4216 ft) above sea level. The total population of the town is about 103,965 people; by using conversion factor for 2014/15 of SNNPR pregnant women in the town it is expected to be 3296 [9]. The three health institutions are the only institutions which provide ANC service for pregnant women in Arba Minch town. The ANC service is provided by midwives who had got special training on focused antenatal care model.
2.2. Study Design. Institution-based, cross-sectional study design was employed.

2.3. Study Participants. The study participants for this study were pregnant women who were attending antenatal care at the selected health institutions during the study period.

2.4. Inclusion Criteria. Pregnant women who reside in Arba Minch for more than six months and who came for ANC during the study period were included in the study.

2.5. Exclusion Criteria. Pregnant women who were seriously ill during the survey were excluded.

2.6. Sample Size and Sampling Procedure. A sample size of 332 was calculated using single proportion formula assuming $16.6 \%$ proportion of anemia in pregnancy (from previous study in Ethiopia [10]) at a $95 \%$ confidence limit, $80 \%$ power, and $4 \%$ margin of error and adding $10 \%$ as contingency for nonresponse.

We have reviewed the last year records of monthly flow of pregnant women for ANC utilization in the three health institutions (340 attendees from Arba Minch General Hospital, 220 from Arba Minch Health Center, and 200 attendees from Secha Health Center). The calculated sample size (332) was proportionally allocated to these three health institutions based on the above records: 149 pregnant women for Arba Minch General Hospital, 96 for Arba Minch Health Centre, and 87 for Secha Health Center. Then, after systematic random sampling technique was employed, for instance, in the case of Arba Minch Hospital, the total monthly number of mothers who attended ANC (340) was divided into the current allocated sample size (149) to get the interval that is two, and then lottery method was used to get the random start. Therefore, randomly selected starting point was number two. The interview was started from the second mother, and then every two mothers were interviewed till the allocated sample was achieved. The same method was applied across the rest centres (Figure 1).

2.7. Data Collection. A structured pretested intervieweradministered questionnaire was used to obtain sociodemographic information and present and past obstetric history in pregnant women. To obtain dietary habit, standard food frequency questionnaire adjusted for local food item was adapted and used to assess the usual intake of various food groups for the past one month with their respective consumption frequency [10]. The questionnaire was developed in English and then translated into Amharic language for simplicity then back-translated to English language for its consistency by two different language expert individuals who speak both English and Amharic fluently. Pretesting of the questionnaire was done on $5 \%$ of the sample size among ANC attendees who were not included in the study; that was a week before commencement of the actual data collection. To ensure reliable data collection and attain standardization and maximize interviewer reliability, midwives who speak both Amharic and the local language (Gamogna) were recruited and given training on data collection procedure. 


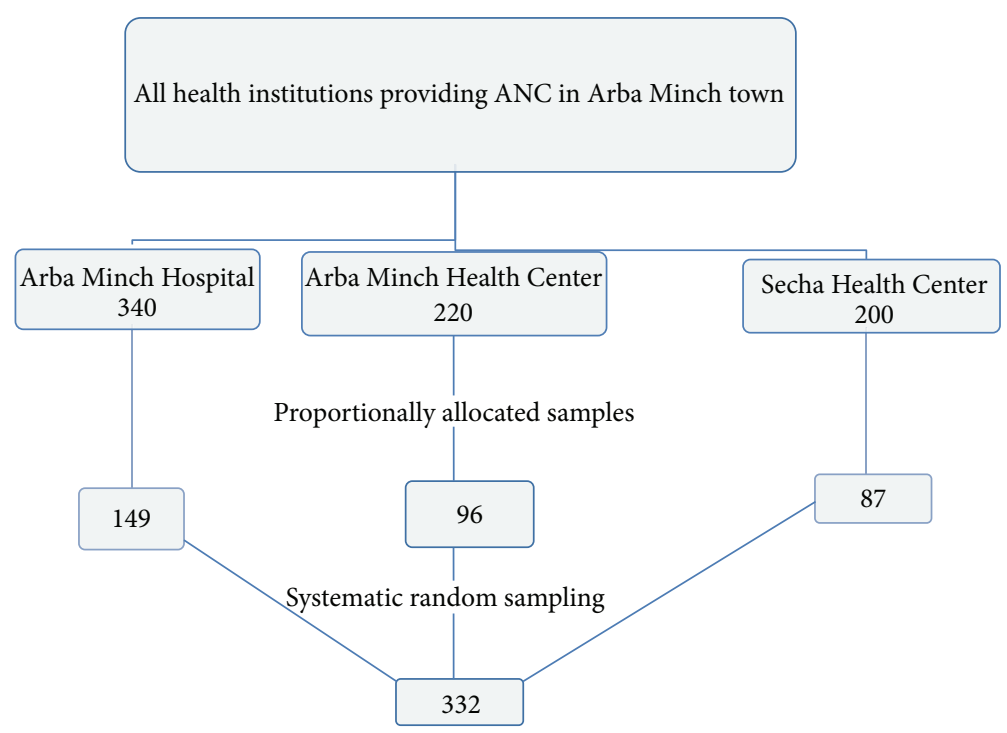

FIGURE 1: Schematic presentation of sampling procedure in public health institutions of Arba Minch town, $2014(n=332)$.

Exit interview was done. The data collectors were regularly supervised for proper data collection; all the questionnaires were checked for completeness and consistency in daily basis.

2.8. Specimen Collection and Processing. The specimen collection process in the three health institutions was carried out by two trained laboratory technologists. Each step of specimen collection, processing, and analysis was supervised by experienced and trained laboratory technologist supervisors. The blood for hematocrit/packed cell volume (PCV) measurement was done based on the Standard Operational Procedures (SOPs).

A venous blood sample was taken from the study participants; using heparinized hematocrit tube, three-fourths of the tube was filled and labeled with identification number. The capillary tube after being sealed at one end was centrifuged in the microhematocrit centrifuge at $10,000 \mathrm{~g}$ for 5 minutes. Then, the result was read using hematocrit reader.

Stool samples were collected by using a clean and labeled container from the study participants. A portion of the stool was processed with direct microscopic technique to detect intestinal parasites immediately. For detection of helminths, eggs, larvae, and cysts of protozoan parasites, the samples were examined microscopically first with $10 \mathrm{x}$ and then with $40 \mathrm{x}$ objective. The remaining part of the sample was emulsified in a $10 \%$ formalin solution.

Stool examinations were done using formal ether concentration technique, which is considered the most sensitive for most intestinal helminthes. The same method was carried out across all centres.

The hematocrit values in our study area were adjusted in line with the WHO graded adjustment for altitudes; since the altitude of our study area is 4216 feet above sea level, the normal increase for hematocrit values related to long-term exposure is $1 \%$. Therefore, the value is adjusted with the given range [11].

\subsection{Operational Definitions and Definition of Terms}

Anemia in Pregnancy. It is when the hematocrit value for a pregnant woman is less than $33 \%$ irrespective of her gestational age [11].

Public Health Importance of Anemia. It is a mild public health problem, when prevalence of anemia is $<20 \%$; a moderate public health problem, when the prevalence of anemia is between 20 and 40\%; a severe public health problem, when the prevalence of anemia is $>40 \%$ [11].

Mild Anemia. Hematocrit value is $\geq 30 \%$ and $<33 \%$.

Moderate Anemia. Hematocrit value is $\geq 21 \%$ and $<30 \%$.

Severe Anemia. Hematocrit value is from $<21 \%$.

Eating Habits. Different eating habits include eating animal foods, green leafy vegetables, taking fruit after meal, and drinking tea/coffee; this is measured by using food frequency questioner [10].

Permanent Resident. Pregnant women lived at least six months in the study area.

Monthly Income of the Family. Monthly income of the family is <1000 Ethiopian Birr (low), 1000-2575 Ethiopian Birr (medium), and $>2575$ Ethiopian Birr (high).

2.10. Data Analysis. Data was entered to Epi Info version 3.5.3 software and then exported to SPSS version 20 statistical packages for analysis. Descriptive statistics were done and summarized by frequencies and proportion for categorical predictors. The presence of association was assessed using 
bivariate analysis and associations with a $p$ value $<0.05$ considered as statistically significant. Multivariate logistic regression was used to control confounding effects and the strength of association was estimated in odds ratio and its $95 \%$ confidence interval.

2.11. Ethical Consideration. Ethical approval was obtained from Joint MPH program, Arba Minch University, and Addis Continental Institute of Public Health Institutional Ethical Review Committee. Official letter to the hospital and health centres was obtained from College of Medicine and Health Sciences, Arba Minch University. To ensure confidentiality, it was anonymous type whereby names of the study subjects were not written on the questionnaire. Written consent from the study participants was obtained after they were briefed about the research intent and asked for their willingness to participate in the study. Their right of denial to participate in the study was also assured.

\section{Result}

3.1. Sociodemographic Characteristics of Study Subjects. A total of 332 representative ANC attendees participated in the study yielding the response rate of $100 \%$.

The median age of the participants was $25 \pm 4.28$. Majority, 256 (77.1\%), of the participants were within the age range of 20-29. Three hundred and twenty-five (97.9\%) of the attendees were married but only four $(1.2 \%)$ were single. With regard to religion, 174 (52.4\%) were Protestants followed by Orthodox Christians, 147 (44.3\%). Pertaining to educational status, 103 (31\%) of the participants achieved secondary school and above. However, 62 (18.7\%) had no formal education. The mean family size in this study group is $3.51 \pm 1.66$. One hundred and eighteen (35.5\%) and 80 (24.1\%) of the attendees had a family size of less than or equal to two and greater than or equal to five, respectively (Table 1).

3.2. Obstetrics and Medical History. Two hundred and seven (62.3\%) of the ANC attendees had previous history of pregnancy. From those who had previous history of pregnancy, $51(24.6 \%)$ and $63(32.8 \%)$ had history of miscarriage or wilful abortion and at least history of one child, respectively. One hundred and twenty-five (69.1\%) had their last births in health facilities. Fifteen (4.5\%) of the ANC attendees had history of bleeding on the current pregnancy. One hundred and seventy-six (89.3\%) had history of ANC follow-up in the previous pregnancy. From those who had history of birth, $28(13.5 \%)$ and $179(86.5 \%)$ had birth interval of less than two years and more than two years between the last and the current pregnancy, respectively.

More than half of the ANC attendees, 202 (60.8\%), had history contraceptive use. More than quarter, 103 (31\%), of the participants had history of malaria attack in the last one year. About 123 (38.0\%) were using iron during the current pregnancy. Concerning gestational age, 48 (14.5\%), 178 (53.6\%), and 106 (31.9\%) were in first, second, and third trimester of pregnancy, respectively (Table 2).
TABLE 1: Sociodemographic characteristics of ANC attendees in government health institutions of Arba Minch town, February to April $2015(n=332)$.

\begin{tabular}{|c|c|c|}
\hline Variables & Number & $\%$ \\
\hline \multicolumn{3}{|l|}{ Age } \\
\hline $15-19$ & 32 & 9.6 \\
\hline $20-29$ & 256 & 77.1 \\
\hline 30 and above & 44 & 13.3 \\
\hline \multicolumn{3}{|l|}{ Marital status } \\
\hline Single & 4 & 1.2 \\
\hline Married & 325 & 97.9 \\
\hline Divorced & 3 & 0.9 \\
\hline \multicolumn{3}{|l|}{ Religion } \\
\hline Orthodox & 147 & 44.3 \\
\hline Protestant & 174 & 52.4 \\
\hline Muslim & 11 & 3.3 \\
\hline \multicolumn{3}{|l|}{ Educational status } \\
\hline No formal education & 62 & 18.7 \\
\hline Primary & 88 & 26.5 \\
\hline Secondary & 79 & 23.8 \\
\hline Above secondary & 103 & 31 \\
\hline \multicolumn{3}{|l|}{ Family size } \\
\hline$\leq 2$ & 118 & 35.5 \\
\hline $3-4$ & 134 & 40.4 \\
\hline$\geq 5$ & 80 & 24.1 \\
\hline \multicolumn{3}{|l|}{ Ethnicity } \\
\hline Gamo & 215 & 64.8 \\
\hline Wolayita & 31 & 9.3 \\
\hline Amhara & 35 & 10.5 \\
\hline Gofa & 18 & 5.4 \\
\hline Others* & 33 & 10 \\
\hline
\end{tabular}

* Gurage, Oromo, Tigray, Konso, Burji, Derashe, Ari, Gidicho, Zayise, Oyida, Amaro, and Sidama.

Prevalence of Anemia. About one-third, 109 (32.8\%), of the 332 ANC attendees were anemic (hematocrit $<33 \%$ ). From those who were anemic, the majority, 57 (52.3\%), were mild (hematocrit value $\geq 30 \%$ and $<33 \%$ ) and $4(3.7 \%)$ were severely anemic (hematocrit value $<21 \%$ ). Eleven $(3 \%)$ of the pregnant women were found to be HIV positive. Giardia lamblia, 30 (9\%); Entamoeba histolytica, 5 (1.5\%); hookworm, $2(0.6 \%)$, were among intestinal parasites detected in the pregnant women (Table 3).

Factors Associated with Anemia among Pregnant Women. Factors associated with anemia in pregnancy were assessed. During the bivariate analysis, educational status, family size, iron supplementation on current pregnancy, and monthly income had statistically significant association with anemia in pregnancy (Tables 4-6).

In multivariate logistic regression, monthly income of the family (AOR $=4.0$; 95\% CI: 5.62-11.01), family size (AOR = 2.8; 95\% CI: $1.17-6.8)$, birth interval $(\mathrm{AOR}=3.1 ; 95 \% \mathrm{CI}$ : 6.01, 10.23), iron tablet supplementation $(\mathrm{AOR}=2.31 ; 95 \%$ CI: 7.21, 9.31), and eating food made from "Enset" and its 
TABLE 2: Obstetrics related characteristics among ANC attendees in health institutions of Arba Minch town, February to April 2015 ( $n=$ 332).

\begin{tabular}{|c|c|c|}
\hline Variables & Number & $\%$ \\
\hline \multicolumn{3}{|c|}{ History of previous pregnancy } \\
\hline Yes & 207 & 62.3 \\
\hline No & 125 & 37.7 \\
\hline \multicolumn{3}{|l|}{ History of abortion } \\
\hline Yes & 51 & 24.6 \\
\hline No & 156 & 75.4 \\
\hline \multicolumn{3}{|l|}{ Number of children } \\
\hline 1 & 63 & 32.8 \\
\hline $2-3$ & 102 & 53.1 \\
\hline$\geq 4$ & 27 & 14.1 \\
\hline \multicolumn{3}{|c|}{ Birth interval between the last and current } \\
\hline Primigravida & 125 & 37.7 \\
\hline$<2$ years & 28 & 13.5 \\
\hline$>2$ years & 179 & 86.5 \\
\hline \multicolumn{3}{|l|}{ Parity } \\
\hline Nullipara (0) & 125 & 37.6 \\
\hline Primipara (1) & 28 & 8.4 \\
\hline Multipara (2-4) & 159 & 47.9 \\
\hline Grand multipara $(\geq 5)$ & 30 & 9.0 \\
\hline \multicolumn{3}{|l|}{ Gestational age } \\
\hline 1st trimester & 48 & 14.5 \\
\hline 2nd trimester & 178 & 53.6 \\
\hline 3rd trimester & 103 & 31.9 \\
\hline \multicolumn{3}{|c|}{ Place of delivery of previous pregnancy } \\
\hline Home & 64 & 30.9 \\
\hline Health facility & 143 & 69.1 \\
\hline \multicolumn{3}{|c|}{ ANC follow-up in previous pregnancy } \\
\hline Yes & 176 & 89.3 \\
\hline No & 21 & 10.7 \\
\hline \multicolumn{3}{|c|}{ Bleeding on current pregnancy } \\
\hline Yes & 15 & 4.5 \\
\hline No & 317 & 95.5 \\
\hline \multicolumn{3}{|l|}{ Contraceptive use } \\
\hline Yes & 202 & 60.8 \\
\hline No & 130 & 39.2 \\
\hline \multicolumn{3}{|l|}{ Malaria in the last one year } \\
\hline Yes & 103 & 31 \\
\hline No & 229 & 69 \\
\hline \multicolumn{3}{|c|}{ Iron supplementation on current pregnancy } \\
\hline Yes & 123 & 37 \\
\hline No & 209 & 63 \\
\hline
\end{tabular}

products $(\mathrm{AOR}=5.11 ; 95 \% \mathrm{CI}: 16.18,21.35)$ were found to be independent predictors of anemia in pregnancy (Table 7).

\section{Discussion}

The current study assessed the prevalence of anemia and its associated risk factors among pregnant women attending
TABLE 3: Laboratory findings of ANC attendees in government health institutions of Arba Minch town, February to April 2015 ( $n=$ 332 ).

\begin{tabular}{lcc}
\hline Variable & Number & $\%$ \\
\hline HIV serostatus & 321 & \\
$\quad$ Negative & 11 & 96.7 \\
Positive & & 3.3 \\
Stool examination & 30 & \\
Giardia lamblia & 2 & 0.6 \\
Hookworm & 1 & 0.3 \\
Ascaris lumbricoides & 5 & 1.5 \\
Entamoeba histolytica & 2 & 0.6 \\
Taenia species & 291 & 87.7 \\
No parasite & &
\end{tabular}

TABLE 4: Sociodemographic factors associated with anemia in pregnancy among ANC attendees in government health institutions of Arba Minch town from February to April $2015(n=332)$.

\begin{tabular}{|c|c|c|c|}
\hline \multirow{2}{*}{ Variables } & \multicolumn{2}{|c|}{ Anemia } & \multirow{2}{*}{ COR $(95 \% \mathrm{CI})$} \\
\hline & Yes & No & \\
\hline \multicolumn{4}{|l|}{ Occupation } \\
\hline House wife & $56(33.5 \%)$ & $111(66.5 \%)$ & 1.00 \\
\hline Civil servant & $13(20.3)$ & $51(79.7 \%)$ & $0.5(0.25-1.01)$ \\
\hline Merchant & $18(37.5 \%)$ & $30(62.5 \%)$ & $1.2(0.61-2.32)$ \\
\hline Day labourer & $12(60 \%)$ & $8(40 \%)$ & $2.9(1.15-7.69)$ \\
\hline Others & $10(30.3 \%)$ & $23(69.7 \%)$ & $0.9(0.38-1.94)$ \\
\hline \multicolumn{4}{|l|}{ Monthly income } \\
\hline$<1000$ ETB & $61(41.2 \%)$ & $87(58.8)$ & $3(7.41-10.67)$ \\
\hline $1000-2575$ ЕTВ & $38(36.2 \%)$ & $67(63.8 \%)$ & $0.81(0.48-1.35)$ \\
\hline$>2575$ ETB & $10(12.7 \%)$ & $69(87.3 \%)$ & 1 \\
\hline \multicolumn{4}{|l|}{ Educational status } \\
\hline Illiterate & $29(46.8 \%)$ & $33(53.2 \%)$ & 1.00 \\
\hline Primary & $29(33 \%)$ & $59(67 \%)$ & $0.44(0.18-1.05)$ \\
\hline Secondary & $26(32.9 \%)$ & $53(67.1 \%)$ & $0.66(0.31-1.39)$ \\
\hline Above secondary & $25(24.3 \%)$ & $78(75.7 \%)$ & $0.36(0.18-0.71)$ \\
\hline \multicolumn{4}{|l|}{ Marital status } \\
\hline Married & $105(32.3 \%)$ & $220(67.7 \%)$ & 1.00 \\
\hline Others & $4(57.1 \%)$ & $3(42.9 \%)$ & $2.8(0.61-12.71)$ \\
\hline \multicolumn{4}{|l|}{ Family size } \\
\hline$\leq 2$ & $35(29.7 \%)$ & $83(70.3 \%)$ & 1.00 \\
\hline $3-4$ & $40(29.9 \%)$ & $94(70.1 \%)$ & $1.5(0.69-3.18)$ \\
\hline$\geq 5$ & $34(42.5 \%)$ & $46(57.5 \%)$ & $2.1(6.42-10.83)$ \\
\hline
\end{tabular}

ANC in government institutions of Arba Minch town, Gamo Gofa zone, Southern Ethiopia. The overall prevalence of anemia among pregnant women attending ANC in the current study was found to be $32.8 \%$ which is lower than a study conducted in India (87-100\%), Boditi (61.6\%), and Gode town, Eastern Ethiopia (56.8\%) [12-15]. This discrepancy could be resulting from geographical variation of factors across different areas and due to time gap between the current study and the 2011 Ethiopian Demographic and Health Survey. 
TABLE 5: Obstetrics factors associated with anemia in pregnancy among ANC attendees in government health institutions of Arba Minch town from February to April $2015(n=332)$.

\begin{tabular}{|c|c|c|c|}
\hline \multirow{2}{*}{ Variables } & \multicolumn{2}{|c|}{ Anemia } & \multirow{2}{*}{$\operatorname{COR}(95 \% \mathrm{CI})$} \\
\hline & Yes & No & \\
\hline \multicolumn{4}{|l|}{ Trimester } \\
\hline First & $12(25 \%)$ & $36(75 \%)$ & 1.00 \\
\hline Second & $65(36.5 \%)$ & $113(63.5 \%)$ & $1.7(0.84-3.55)$ \\
\hline Third & $32(30.2 \%)$ & $74(69.8 \%)$ & $1.3(0.59-2.81)$ \\
\hline \multicolumn{4}{|c|}{ History of malaria attack (last 1 year) } \\
\hline No & $78(34.1 \%)$ & $151(65.9 \%)$ & 1.00 \\
\hline Yes & $31(30.1 \%)$ & $72(69.9 \%)$ & $0.83(0.51-1.37)$ \\
\hline \multicolumn{4}{|c|}{ Intestinal parasite on current pregnancy } \\
\hline No & $97(33.3 \%)$ & $194(66.7 \%)$ & 1.00 \\
\hline Yes & $12(29.3 \%)$ & $29(70.7 \%)$ & $0.83(0.41-1.69)$ \\
\hline \multicolumn{4}{|c|}{ HIV serostatus } \\
\hline Negative & $106(33 \%)$ & $215(67 \%)$ & 1.00 \\
\hline Positive & $3(27.3 \%)$ & $8(72.7 \%)$ & $0.76(0.19-2.93)$ \\
\hline \multicolumn{4}{|c|}{ Iron supplementation on current pregnancy } \\
\hline No & $73(34.9 \%)$ & $136(65.1 \%)$ & $1.9(6.4-9.10)$ \\
\hline Yes & $36(29.3 \%)$ & $87(70.7 \%)$ & 1 \\
\hline \multicolumn{4}{|c|}{ Birth interval } \\
\hline$\leq 2$ years & $15(53.6 \%)$ & $13(46.4 \%)$ & $2.3(4.41-7.23)$ \\
\hline$>2$ years & $52(29.1 \%)$ & $127(70.9 \%)$ & 1 \\
\hline
\end{tabular}

TABLE 6: Dietary habits associated with anemia in pregnancy among ANC attendees in government health institutions of Arba Minch town from February to April $2015(n=332)$.

\begin{tabular}{|c|c|c|c|}
\hline \multirow{2}{*}{ Variables } & \multicolumn{2}{|c|}{ Anemia } & \multirow{2}{*}{ COR $(95 \% \mathrm{CI})$} \\
\hline & Yes & No & \\
\hline \multicolumn{4}{|c|}{ Eating food made from "Enset" and its products } \\
\hline Twice/month & $10(43.5 \%)$ & $13(56.5 \%)$ & 1.00 \\
\hline 1-2 per week & $25(35.7 \%)$ & $45(64.3 \%)$ & $0.72(0.27-1.88)$ \\
\hline 3-4 per week & $15(17.9 \%)$ & $69(82.1 \%)$ & $0.28(0.10-0.76)$ \\
\hline Once/day & $38(36.5 \%)$ & $66(63.5 \%)$ & $0.75(0.30-1.87)$ \\
\hline$>1$ per day & $21(41.2 \%)$ & $30(58.8 \%)$ & $0.91(0.34-2.46)$ \\
\hline \multicolumn{4}{|c|}{ Eating food made from cereals, grains } \\
\hline 2 times/wk & $7(43.8 \%)$ & $9(56.2 \%)$ & 1.00 \\
\hline $3-4 / w k$ & $7(33.3 \%)$ & $14(66.7 \%)$ & $0.64(0.17-2.45)$ \\
\hline Once/day & $22(18.3 \%)$ & $98(81.7 \%)$ & $0.28(0.09-0.86)$ \\
\hline$>1 /$ day & $73(32.8 \%)$ & $102(67.2 \%)$ & $0.92(0.33-2.58)$ \\
\hline \multicolumn{4}{|c|}{ Drinking tea or coffee } \\
\hline $2 /$ month or less & $6(2.4 \%)$ & $19(76 \%)$ & 1.00 \\
\hline $1-4 /$ wk & $6(20 \%)$ & $24(80 \%)$ & $0.79(0.22-2.85)$ \\
\hline 1/day & $33(25 \%)$ & $99(75 \%)$ & $1.1(0.38-2.86)$ \\
\hline$>1 /$ day & $64(44.1 \%)$ & $81(55.9 \%)$ & $2.5(0.94-6.63)$ \\
\hline \multicolumn{4}{|l|}{ Eating fruit } \\
\hline$\leq 2 \mathrm{wk}$ & $20(45.5 \%)$ & $24(54.5 \%)$ & 1.00 \\
\hline $3-4 / w k$ & $25(30.5 \%)$ & $57(69.5 \%)$ & $0.53(0.25-1.12)$ \\
\hline $1 /$ day & $38(28.1 \%)$ & $97(71.9 \%)$ & $0.47(0.23-0.95)$ \\
\hline$>1 /$ day & $25(35.7 \%)$ & $45(64.3 \%)$ & $0.67(0.31-1.44)$ \\
\hline \multicolumn{4}{|c|}{ Eating beef, goat, chicken, or other kinds of organ meat } \\
\hline Never & $15(23.1 \%)$ & $50(76.9 \%)$ & 1.00 \\
\hline $1-2 /$ month & $55(37.4 \%)$ & $92(62.6 \%)$ & $1.9(1.02-3.88)$ \\
\hline 1-2/week & $30(34.9 \%)$ & $56(65.1 \%)$ & $1.8(0.86-3.69)$ \\
\hline$\geq 3 /$ wk & $9(26.5 \%)$ & $25(73.5 \%)$ & $1.2(0.46-3.12)$ \\
\hline
\end{tabular}


TABLE 7: Multivariate logistic regression analysis results showing factors associated with anemia in pregnancy among ANC attendees in government health institutions of Arba Minch town from February to April $2015(n=332)$.

\begin{tabular}{|c|c|c|c|c|}
\hline \multirow{2}{*}{ Variables } & \multicolumn{2}{|c|}{ Anemia } & \multirow{2}{*}{ COR $(95 \% \mathrm{CI})$} & \multirow{2}{*}{$\operatorname{AOR}(95 \% \mathrm{CI})$} \\
\hline & Yes & No & & \\
\hline \multicolumn{5}{|l|}{ Monthly income } \\
\hline$<1000$ Birr & $61(41.2 \%)$ & $87(58.8)$ & $3(7.41-10.67)$ & $4.0(5.62-11.01)$ \\
\hline 1000-2575 Birr & $38(36.2 \%)$ & $67(63.8 \%)$ & $0.81(0.48-1.35)$ & $0.9(0.54-1.75)$ \\
\hline$>2575$ Birr & $10(12.7 \%)$ & $69(87.3 \%)$ & 1 & 1 \\
\hline \multicolumn{5}{|l|}{ Family size } \\
\hline$\leq 2$ & $35(29.7 \%)$ & $83(70.3 \%)$ & 1.00 & 1.00 \\
\hline $3-4$ & $40(29.9 \%)$ & $94(70.1 \%)$ & $1.01(0.59-1.73)$ & $1.5(0.69-3.18)$ \\
\hline$\geq 5$ & $34(42.5 \%)$ & $46(57.5 \%)$ & $2.1(6.42-10.83)$ & $2.8(1.17-6.80)$ \\
\hline \multicolumn{5}{|c|}{ Iron supplementation on current pregnancy } \\
\hline No & $73(34.9 \%)$ & $136(65.1 \%)$ & $1.9(6.4-9.10)$ & $2.31(7.21,9.31)$ \\
\hline Yes & $36(29.3 \%)$ & $87(70.7 \%)$ & 1 & 1 \\
\hline \multicolumn{5}{|l|}{ Birth interval } \\
\hline$\leq 2$ years & $15(53.6 \%)$ & $13(46.4 \%)$ & $2.3(4.41-7.23)$ & $3.1(6.01,10.23)$ \\
\hline$>2$ years & $52(29.1 \%)$ & $127(70.9 \%)$ & $0.81(0.49-1.32)$ & 1 \\
\hline \multicolumn{5}{|c|}{ Eating food made from "Enset" and its products } \\
\hline Twice/month & $10(43.5 \%)$ & $13(56.5 \%)$ & 1.00 & 1.00 \\
\hline 1-2 per week & $25(35.7 \%)$ & $45(64.3 \%)$ & $0.72(0.27-1.88)$ & $0.22(0.07-0.73)$ \\
\hline 3-4 per week & $15(17.9 \%)$ & $69(82.1 \%)$ & $0.28(0.10-0.76)$ & $0.12(0.03-0.39)$ \\
\hline Once/day & $38(36.5 \%)$ & $66(63.5 \%)$ & $0.75(0.30-1.87)$ & $0.36(0.12-1.11)$ \\
\hline$>1$ per day & $21(41.2 \%)$ & $30(58.8 \%)$ & $0.91(0.34-2.46)$ & $0.17(0.05-0.62)$ \\
\hline
\end{tabular}

However, the prevalence of anemia in the current study was found to be higher as compared to the study conducted in Addis Ababa (21.3\%) and Gondar Northwest Ethiopia $(16.6 \%)[10,14,16]$. In addition, the current prevalence of anemia is also higher than the national anemia prevalence (22\%) [6]. This might be attributed to the fact that the majority of the participants in the current study consume plant based foods as a staple food which is rich in nonheme iron with bioavailability of not more than $10 \%$. The high consumption of tea and coffee in the study area might reduce the bioavailability of the nonheme iron from plant based staple foods.

In the current study among the pregnant women, mild anemia was found to be common and followed by moderate anemia. Consistent result was reported from studies conducted in some African countries and elsewhere in the world [12-15, 17-21].

Monthly income was significantly associated with anemia in pregnancy. Pregnant women who had low monthly family income (less than 2575 Ethiopian Birr) were four times more likely to be anemic as compared to those with high monthly family income (greater than 2575 Ethiopian Birr). This is in agreement with some studies $[10,14]$. This could be explained by the reality that more than $57 \%$ of the total expenditure among Ethiopians is spent on food [15, 22]. Hence, pregnant women with low income groups could not get adequate nutrition so that they were at risk of anemia.

Pregnant women having birth interval less than two years were at higher risk of becoming anemic as compared to those with birth interval more than two years. This finding is consistent with a study conducted in Saudi Arabia [23]. This might be related with decreased iron store of women due to occurrence of pregnancy in quick succession between subsequent pregnancies.

Pregnant women who have had no iron supplementation on the current pregnancy were in about two times higher risk of developing anemia as compared to those who have had iron supplementation. This finding is consistent with the findings from Gode town (Eastern Ethiopia) and Vietnam $[15,24]$, which indicated that lack of iron supplementation was among the most significant risk factors for developing anemia during pregnancy. This is likely due to the fact that the requirement for iron increases for pregnant women as compared to nonpregnant women; this is associated with the reality that blood volume increases by $50 \%$ during pregnancy and the requirement of iron to growing fetus and placenta. Therefore, supplementation of iron during pregnancy is crucial to fulfil this need.

In this study, family size was also significantly associated with anemia; pregnant women with family size greater than 5 were at higher risk of developing anemia than those with family size less than five. This finding is comparable with a study conducted in Shala woreda (West Arsi) in which the prevalence of anemia was higher among women with family size $>5$ as compared to their counterparts [25]. The direct relationship of family size with anemia in this study could be associated with food insecurity for large family size.

Study Limitations. This study is limited by its cross-sectional nature, whereby it may not explain the temporal relationship 
between the outcome variable and some explanatory variables; this limits interpretation of the estimated associations. Recall bias might be introduced on food frequency. Thus, the findings of this study should be interpreted within these limitations.

\section{Conclusion}

The overall prevalence of anemia among women attending ANC in government health institutions of Arba Minch town was $32.8 \%$. Anemia is a moderate public health problem in Arba Minch, which is by far higher than the national prevalence, $22 \%$. Monthly income, family size, birth interval, and iron supplementation were significantly associated with anemia. We recommend awareness creation on birth spacing and nutritional counselling on consumption of iron-rich foods and iron supplementation to prevent anemia among pregnant women with special emphasis on those from low income group and large family size.

\section{Conflict of Interests}

The authors declare that they have no conflict of interests.

\section{Authors' Contribution}

Alemayehu Bekele designed, conducted, and analyzed the data as part of his thesis work. Aleme Mekuria assisted in the design of the study and conducted critical review. Marelign Tilahun assisted in and supervised the design of the study. All the authors read and approved the paper.

\section{Acknowledgments}

The authors are very thankful to Joint MPH Program, Arba Minch University, and Addis Continental Institute of Public Health for enabling them to go through this research undertaking process. They would like also to extend their heartfelt thanks and appreciation to Arba Minch College of Health Sciences for the financial support. Last but not least, their special thanks go to the study participants for their willingness to share their experience and giving time for the interview.

\section{References}

[1] E. McLean, M. Cogswell, I. Egli, D. Wojdyla, and B. De Benoist, "Worldwide prevalence of anaemia, WHO Vitamin and Mineral Nutrition Information System, 1993-2005," Public Health Nutrition, vol. 12, no. 4, pp. 444-454, 2009.

[2] WHO/CDC, Worldwide Prevalence of Anemia 1993-2005 WHO Global Database on Anemia, WHO Press, Geneva, Switzerland, 2008.

[3] Y. Balarajan, U. Ramakrishnan, E. Özaltin, A. H. Shankar, and S. V. Subramanian, "Anaemia in low-income and middle-income countries," The Lancet, vol. 378, no. 9809, pp. 2123-2135, 2011.

[4] WHO, Micronutrients Indicators Haemoglobin Concentrations for the Diagnosis of Anemia and Assessment of Severity, Vitamin and Mineral Nutrition Information System, 2011.
[5] A. Meseret, B. Enawgaw, A. Gelaw, T. Kena, M. Seid, and Y. Olkeba, "Prevalence of anemiaand associated risk factors among pregnant women attending antenatal care in Azezo Health Center, Gondar town, Northwest Ethiopia," Journal of Interdisciplinary Histopathology, vol. 1, no. 3, pp. 137-144, 2013.

[6] CSA, Ethiopia Demographic and Health Survey: Preliminary Report, CSA, Addis Ababa, Ethiopia, 2011.

[7] F. W. Lone, R. N. Qureshi, and F. Emanuel, "Maternal anaemia and its impact on perinatal outcome," Tropical Medicine \& International Health, vol. 9, no. 4, pp. 486-490, 2004.

[8] J. Jennings and M. B. Hirbaye, Review of Incorporation of Essential Nutrition Actions into Public Health Programs in Ethiopia, section 1-25, The Food and Nutrition Technical Assistance Project (FANTA), Equinet, 2008.

[9] Central Statitical Authority of Ethiopia (CSA), Population and Housing Census of Ethiopia: Ethiopia Statistical Abstract, CSA, Addis Ababa, Ethiopia, 2007.

[10] R. S. Gibson, Principles of Nutritional Assessment, Oxford University Press, New York, NY, USA, 2nd edition, 2005.

[11] WHO, Iron Defficiency Anemia, Assessment, Prevention, and control: A Guide for Program Managers, World Health Organization, Geneva, Switzerland, 2001.

[12] M. Melku, Z. Addis, M. Alem, and B. Enawgaw, "Prevalence and predictors of maternal anemia during pregnancy in Gondar, Northwest Ethiopia: an institutional based cross-sectional study," Anemia, vol. 2014, Article ID 108593, 9 pages, 2014.

[13] P. O. Lokare, V. D. Karanjekar, P. L. Gattani, and A. P. Kulkarni, "A study of prevalence of anemiaand sociodemographic factors associated with anemia among pregnant women in Aurangabad city, India," Annals of Nigerian Medicine, vol. 6, no. 1, pp. 30-34, 2012.

[14] B. Vemulapalli and K. K. Rao, "Prevalence of anemiaamong pregnant women of rural community in Vizianagram, North coastal Andhra Pradesh, India," Asian Journal of Medical Science, vol. 5, no. 2, pp. 21-25, 2014.

[15] K. A. Alene and A. M. Dohe, "Prevalence of anemia and associated factors among pregnant women in an urban area of Eastern Ethiopia," Anemia, vol. 2014, Article ID 561567, 7 pages, 2014.

[16] D. Lelissa, M. Yilma, W. Shewalem et al., "Prevalence of anemia among women receiving antenatal care at Boditii Health Center, Southern Ethiopia," Clinical Medicine Research, vol. 4, no. 3, pp. 79-86, 2015.

[17] A. Hailu Jufar and T. Zewde, "Prevalence of anemia among pregnant women attending antenatal care at Tikur Anbessa Specialized Hospital, Addis Ababa, Ethiopia," Journal of Hematology \& Thromboembolic Diseases, vol. 2, no. 1, article 125, 2013.

[18] C. C. Dim and H. E. Onah, "The prevalence of anemia among pregnant women at booking in Enugu, South Eastern Nigeria," Medscape General Medicine, vol. 9, no. 3, article 11, 2007.

[19] A. Olubukola, A. Odunayo, and O. Adesina, "Anemia in pregnancy at two levels of health care in Ibadan, south west Nigeria," Annals of African Medicine, vol. 10, no. 4, pp. 272-277, 2011.

[20] E. O. Uche-Nwachi, A. Odekunle, S. Jacinto et al., "Anaemia in pregnancy: associations with parity, abortions and child spacing in primary healthcare clinic attendees in Trinidad and Tobago," African Health Sciences, vol. 10, no. 1, pp. 66-70, 2010.

[21] K. S. Okunade and M. A. Adegbesan-Omilabu, "Anemia among pregnant women at the booking clinic of a teaching hospital in South-Westeren Nigeria," International Journal of Medicine and Biomedical Research, vol. 3, no. 2, pp. 114-120, 2014. 
[22] CSA, Ethiopia Demographic and Health Survey, CSA, Addis Ababa, Ethiopia, 2011.

[23] A. M. Abdelhafez and S. S. El-Soadaa, "Prevalence and risk factors of anemia among a sample of pregnant females attending primary health care centers in Makkah, Saudi Arabia," Pakistan Journal of Nutrition, vol. 11, no. 12, pp. 1113-1120, 2012.

[24] R. Aikawa, N. C. Khan, S. Sasaki, and C. W. Binns, "Risk factors for iron-deficiency anaemia among pregnant women living in rural Vietnam," Public Health Nutrition, vol. 9, no. 4, pp. 443448, 2006.

[25] N. Obse, A. Mossie, and T. Gobena, "Magnitude of anemia and associated risk factors among pregnant women attending antenatal care in Shalla Woreda, West Arsi Zone, Oromia Region, Ethiopia," Ethiopian Journal of Health Sciences, vol. 23, no. 2, pp. 165-173, 2013. 


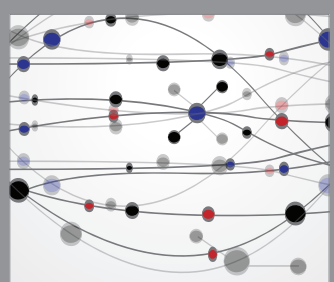

The Scientific World Journal
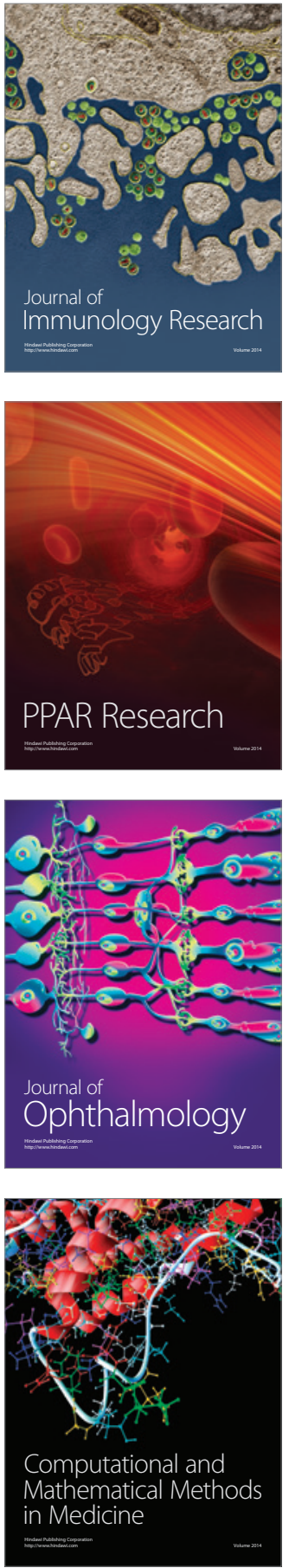

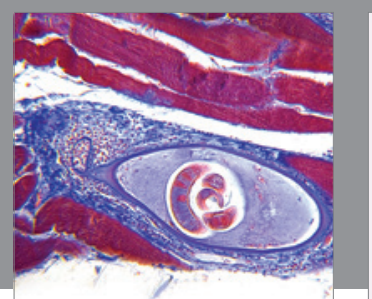

Gastroenterology Research and Practice

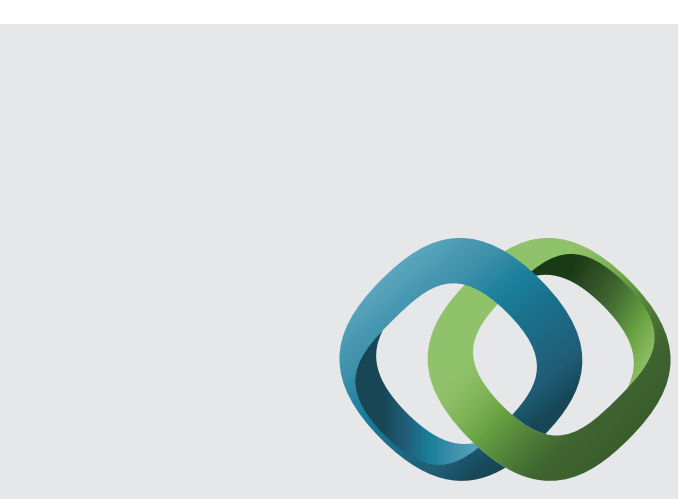

\section{Hindawi}

Submit your manuscripts at

http://www.hindawi.com
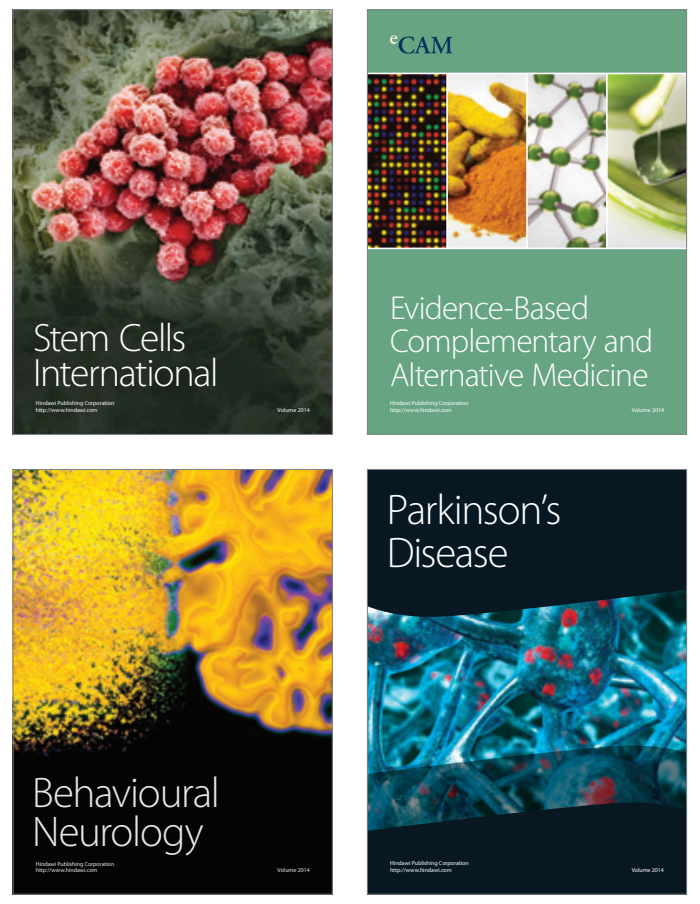
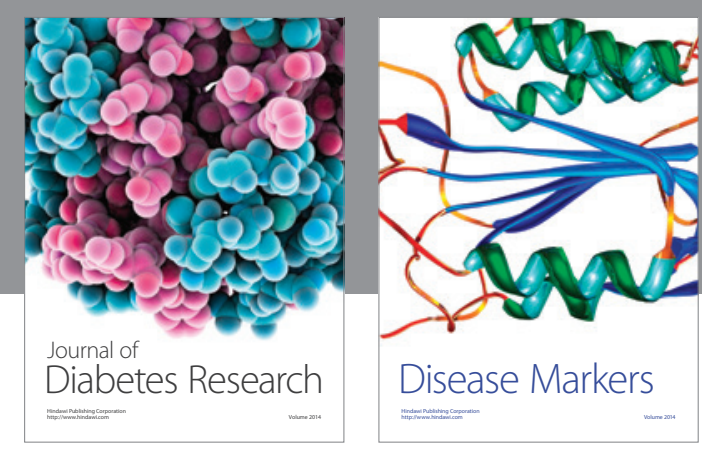

Disease Markers
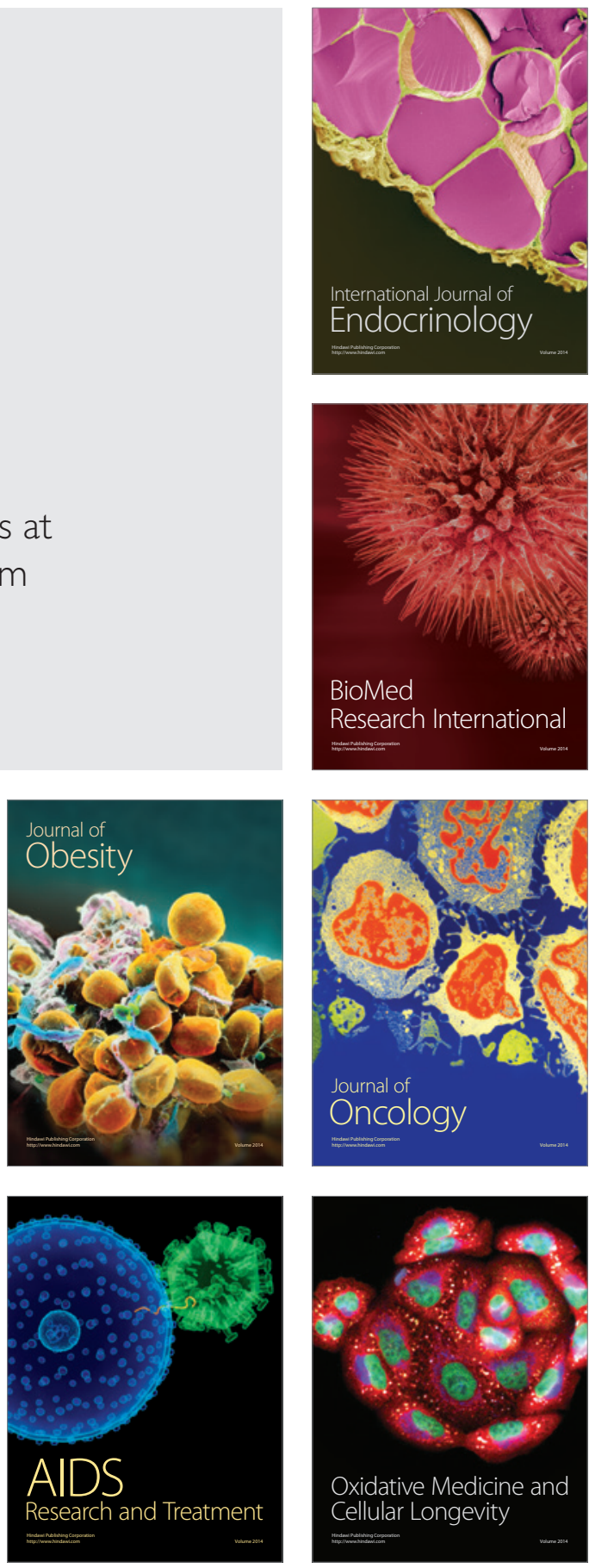